\title{
Nano Technology: The Flipside of Transition Technology
}

\author{
Valsamma K. M.
}

\begin{abstract}
The 21st century world is indisputably at the intersection of a revolutionary era, ushered in by the synergized confluence of biotechnology and nano technology. Whereas the characteristic building blocks that were, manifested in all the traditional evolutionary changes in the Industrial era from flint chips to silicon chips, were the "bulk technologies", now in recent times, in a quick reversal of the situation, the bulk technologies are on the cusp of radically getting replaced by entirely new generation of "molecular technologies". This necessarily pre supposes a shift in the way we look at the manufacturing industry. Molecular manufacturing has in this process come to mean a revolutionary gene-on-a-chip approach which seeks to "eliminate manufacturing industry as we know it. It would also eliminate the rural sector: farms growing food and forest plantations growing wood" [1]. In the Agricultural sector, it would make a sea change as when large slabs of beef or chicken meat grown in vats by in vitro process would be available without growing any cattle or poultry in the farm level . It is estimated that a single animal could provide more than a billion pounds of in vitro meat to feed the world's population for at least several hundred years [2]. Similarly scientists would be in a position to synthesize, wood commensurate with desirable characteristics instead of having to rely on nature's imperfect random variations, all of which are likely to have far reaching implications in land use and sustainability. As a result, unlike as of now, in the nano technology enabled future, "the farm will be a wide area bio-factory that can be monitored and
\end{abstract} managed from a laptop and food will be crafted from designer substances delivering nutrients efficiently to the body". [3], While nanotechnology is admittedly the technology enabled and atomically assembled antithesis to organic agriculture, organic agriculture on the other hand places a premium on the wholesome health-boosting properties of fresh, unprocessed whole foods. In contrast nanotechnology, further seeks to transform the farm as a whole into an automated extension of the high technology factory production line. According to Raymond Ray Kurzweil who has since been hailed by Forbes as "the ultimate thinking machine" as it is the computing power, that renders growth in so many fields of science and technology, these improvements in computing power, ipso facto , translate themselves into exponential advancements in non-computer sciences like nanotechnology, biotechnology, and materials science. Kurzweil has chosen to refer to this concept as the "Law of Accelerating Returns". The goal of Agriculture is to supply all people on the planet with enough food to prevent wide spread hunger and starvation. However, the larger issues of food security are getting worse day by day, resulting in an increase in the number of malnourished persons in the world. The ever increasing population in the developing and less developed countries is also coming in the way, as a major constraint in the eradication of poverty. While there are beneficial attributes of Nano technology there are also pitfalls in its path. David Collingridge, of the University of Aston, has given us a treatise of how two conditions necessary for avoiding

Manuscript received March 9, 2012; revised April 13, 2012.

K. M. Valsamma is with Faculty of Agricultural Engineering, Department of SAC, Kerala Agricultural University, KCAET, Tavanur(email: valsammakm@gmail.com). the undesired consequences of an emerging technology are to be suitably dealt with. In his 1980 book, The Social Control of Technology, what has now come to be known as the Collingridge dilemma is described. Collingridge has made it known, in his book that more often than not, it is one of the recurring dilemmas, "that a technology has, or will have, harmful effects, and it must be possible to change the technology in some way to avoid the effects."[4] Unfortunately, one or both of the conditions precedent to control of technology seldom succeed or are often lacking, and Collingridge has expressed this misfortune in the form of a dilemma, which has now come to be known as Collingridge's dilemma. It has since been argued that in the case of Nano technology, what is being encountered is not merely a dilemma but actually a trilemma. Drexler the ardent proponent of Nanotechnology that he is has also cautioned the world about the other side of Nano technology by coming out with the statement that Nano technology is a technology of "unprecedented power with commensurate dangers and opportunities". In the same vein, Bill Joy Chief Scientist at Sun Microsystems has also voiced his concern, when he says that "our most powerful 21st-century technologies - are threatening to make humans an endangered species."

Index Terms-Nano scale material, precision agriculture, food security, nano technology, bio-technology.

\section{INTRODUCTION}

Agriculture is the backbone of most developing countries, with more than $60 \%$ of the population being reliant on it, for their livelihood. Thanks to the potential of nanotechnology, tomorrow's food chain is going to be designed in a bottom up or top down manner by shaping molecules and atoms. Food will be wrapped in "smart" safety packaging that can detect spoilage or harmful contaminants. Future products will enhance and adjust their color, flavor, or nutrient content to accommodate each consumer's taste or health needs. And in agriculture, nanotechnology promises to reduce pesticide use, improve plant and animal breeding, and create new Nano-bio industrial products. Nanotechnology which is a new and more powerful mode of industrial revolution is capable of bringing wealth, health, and education, without pollution, to every denizen of the planet. It is one of the benign attributes of Nanotechnology that forest no longer will need to be cut or smoke spewed into the air in an effort to turn to agriculture.. This is one of the promises that nanotechnology holds out. The anticipated dividends to which the votaries of nano technology will be eligible in the coming days will be both unprecedented and far beyond the realm of any living memory and human experience so far. At the same time, as Eric Drexler famously put it,nanotechnology, based on nano machines that build with atom-by-atom control, promises great opportunities if used in the right way and, great dangers if abused [5]. Molecular assemblers which the characteristic 
feature of Nanotechnology build materials to order, making matter as controllable and easily reproduced as a software even as wastes and pollution are disassembled in such a way as to recover elements and compounds for reuse. Molecular manufacturing could help us get precisely what we seem to want: high-quality products made at low cost with little environmental impact. The food and agriculture industries have been investing billions of dollars into nanotechnology research, with an unknown number of unlabeled nano food products already on the market. It is estimated that nanotechnology will be used in $40 \%$ of the food industries by 2015 . In the agricultural front there are certain key focus areas that are of utmost relevance, such as the Nanomodification of seed fertilizers and pesticides, not excluding the enabled rearrangement of the DNA of seeds in order to obtain different plant properties including colour, growth season, yield etc. In addition to this, in the new nanotechnology regime, highly potent atomically engineered fertilizers and pesticides will be used to maintain plant growth. In the direction of Food 'fortification, modification, and smart food packaging and tracking, Nanotech companies are gearing up to fortify processed food with nano-encapsulated nutrients, its appearance and taste enhanced by nano-complemented colours, its fat and sugar content either removed or disabled by nano-modification. Again under the category of nano modification, comes Nano-sensors with attendant features tailor made to assess plant growth, $\mathrm{pH}$ levels, the presence of nutrients, moisture, pests or disease and the overall attraction is that all these can be remote controlled, thereby significantly reducing the need for on-farm labour inputs.

Food 'fortification' attempts such as the inclusion of 'medically beneficial' nano-capsules will soon enable chocolate chip cookies or hot chips to be marketed as health promoting or artery cleansing. In the same fashion, it is on the cards that Nanotechnology will also enable junk foods like ice cream and chocolate to be modified to reduce the amount of fats and sugars that the body can absorb. This is sought to be achieved either by replacing some of the fats and sugars with other substances, or by using nano particles to prevent the body from digesting or absorbing these components of the food. In this way, the nano industry has the capability to promote weight reducing vitamin and fibrefortified, fat and sugar-blocked junk food...At present food security in India is under severe stress with availability outstripping demand for recommended quantity of nutrients. What is more and number of malnourished or undernourished persons is increasing every year. Undernourishment is defined as having less than $9200 \mathrm{KJ}$ of food energy per day. In the past four decades, total world food production grew by $145 \%$. In Africa, it went up by $140 \%$, in Latin America by almost $200 \%$, and in Asia by a remarkable $280 \%$. The greatest increases to have been recorded have been in China, with an extraordinary 5-fold increase, mostly occurring in the1980s and 1990s (Pretty, 2003). Moreover, if food plants are to be utilized for production of renewable liquid bio fuel there would be enormous changes in eco systems, destabilizing the natural balance and leading to lower productivity of food crops. As per 2004, FAO estimates $11 \%$ of the world's surface amounting to 1.5 billion ha of arable land was in agricultural use showing a 12\% spurt in agricultural land use since 1961. At the same time the past three decades, had witnessed a doubling of land under irrigation, resulting in a $20 \%$ increase in per capita food production. But we cannot lose sight of the fact that this was at the expense of an 18-fold, increase in fertilizer use. Now when global population has peaked to 7 billion, and climate change is playing havoc on agriculture, it is a different story requiring a global reorientation of priorities, where the direction and focus of future sustainable agriculture are slowly but surely shifting to controlled environment agriculture and matching technology up gradations. The finite world of ours is fast approaching the limits both in terms of the amount of land available for agricultural expansion and in terms of the sustainability of the intensive high input fossil fuel dependent farming systems. We have been obviously sacrificing the long term objective of sustainable agriculture with lowest possible environmental footprint in favor of higher yields for feeding an expanding population that has reached 7 billion. Faced the twin-challenge of global warming and food scarcity, the developing countries are investing ecological farming, taking advantage of the strength of crop bio-technology and Nano technology. The review underpins that there is need for putting in yeoman's effort based on "one health" concept which stands for the health of entire ecosystem, through investing in ecological farming on the strength of Bio Technology and Nano Technology.

\section{POPUlATION GROWTH VERSUS RESOURCES OF THE EARTH}

There were 1 billion people in 1804; 2 billion in 1927; 6 billion in 1999; and 7 billion today. The global food system will experience an unprecedented confluence of pressures over the next 40 years. On the demand side, the fact that many people are likely to be wealthier, will create demand for a more varied, high-quality diet requiring additional resources. On the production side, competition for land, water and energy will intensify, while the effects of climate change will become increasingly apparent. To cope up with this increase, the food production has necessarily to increase by an estimated $70 \%$. Nobel laureate Norman Borlaug, father of Green Revolution had estimated the that by 2025 , average cereal yield must increase by $80 \%$ over the 1990 average.[ IFPRI, ] During the World Food Summit held in Rome in 1996 governments made a firm commitment to halve world hunger by year 2015. The same goal was set in Target 3 of the MDGs .According to the International Food Policy Research Institute, rice production must increase 38\% by 2025 to feed 4 billion rice consumers. FAO had calculated that when the proportion of people living in urban areas increase from about 50 to 70 percent by 2050 the people's diets will also change, shifting to increased proportions of vegetables, fruits and livestock products. According to FAO's Livestock's Long Shadow report, the meat industry adds $18 \%$ of human-related greenhouse gases, measured in CO2equivalent, which is higher than the emissions in the transportation industry. Currently, per capita annual food demand in industrialized countries is 550 $\mathrm{kg}$ of cereal and78 $\mathrm{kg}$ of meat. By contrast, in developing 
countries it is only $260 \mathrm{~kg}$ of cereal and $30 \mathrm{~kg}$ of meat. These food consumption disparities between wealthy and poor people are expected to persist.

\section{Bio TECHNOLOGY.}

The complex and inter- related challenges of global warming and food security can be a combated to a great extent by a combination of bio technology and nano technology. In the past ecological and concerns about croppests have frequently been the drivers of technology based solutions: For example: pesticide inputs substituted by IPM (integrated pest management) and inorganic nitrogen inputs by bio-fertilizers and legume inter cropping... The substitution of inorganic inputs by biological agents can have multiple dividends, for instance: reduced energy use side by side with enhanced environmental credentials by way of reduction or elimination of lingering input residues. Lower costs and improved safety for farmers who would otherwise need many chemical inputs. Thus the threats and opportunities thrown up by the introduction of new crop strains can be met in a pragmatic and positive way through the benign intervention of bio technology.

\section{NANO TEChNOLOGY.}

Nano technology is now being operated on sort of "blackbox" principle. Creating a bio economy is a challenging and complex process involving the convergence of different branches of science. Nano technology of unprecedented power and opportunities .Just as digital electronics has brought an information-processing revolution by handling information quickly and controllably in perfect, discrete pieces of bits and bytes, nanotechnology on the other hand will bring a matter-processing revolution by handling matter quickly and controllably in perfect, discrete pieces of atoms and molecules Whereas the digital revolution was centered on a programmable computer, the nano technological revolution was centered the programmable assembler. In the agri -field Nano enabled physical filters with nanometerscale pores can remove $100 \%$ of bacteria, viruses, and even prions which is a disease-causing agent that is neither bacterial nor fungal nor viral and contains no genetic material. The possibilities of nano are enormous. For instance, if we rearrange the atoms in coal, we can make diamond. Likewise, if we rearrange the atoms in sand and add a few other trace elements, we can make computer chips. If we rearrange the atoms in dirt, water and air we can make potatoes. On the other hand, on the flip side of nano, it has been pointed out that in a hypothetical end-of-theworld scenario, involving molecular nanotechnology, there is the dreaded prospect of what is called "grey goo", with an army of billions of nanobots released to clean up an oil spill, devouring all carbon based objects, instead of just the hydrocarbons of the oil.

\section{CONCLUSION}

The potential advantages that nano technology holds out to the world at large are obviously so many. It offers new tools for the molecular treatment of diseases, rapid disease diagnosis, and most importantly it enhances the ability of plants to absorb nutrients. Smart sensors and smart delivery systems will help the agricultural industry combat viruses and other crop pathogens. In the near future nano-structured catalysts will be available which will increase the efficiency of pesticides and herbicides, allowing lower doses to be used. Nanotechnology will also protect the environment indirectly through the use of alternative (renewable) energy supplies, and filters or catalysts to reduce pollution and clean-up existing pollutants. Precision farming which is on the top of the priority of Nanotechnology-biotechnology combine has the professed long-desired goal of maximizing output (i.e. crop yields) while minimizing input (i.e. fertilizers, pesticides, herbicides, etc.) through recourse to monitoring environmental variables and applying targeted action. In the future, nanotechnology may be able to harness the forces that operate at the scale of the nanometer, such as the van der Waals force, as well as changes in the quantum states of particles, for new engineering purposes holding, out great promise of improvements in the quality of life, including new treatments for disease and greater efficiency in computer data storage and processing. Lederberg has made it known to us [5] notes that the microbial world is evolving at a fast pace, and suggests that our survival may depend upon embracing a "more microbial point of view." The emergence of new infectious agents such as HIV and Ebola demonstrates that we have as yet little knowledge of how natural or technological disruptions to the environment might trigger mutations in known organisms or unknown extant organisms [6-7], producing a limited form of "green goo. Coming to the benign aspects of nanotechnology, ultrafine fibers produced by electro spinning are expected to have a property of a, a very high surface to volume ratio, making electro spun material suitable for activities requiring a high degree of physical contact, such as providing sites for chemical reactions, or the capture of small sized particulate material by physical entanglement - filtration. The use of nano-fiber webs as a filtering medium is well established.

\section{REFERENCES}

[1] A. Richard, Slaughter:Reinventing the Future: Foresight and the Rise of nanotechnology, pp.1-10, 1995.

[2] R. Kurzweil, The Singularity is Near: Penguin Books, ISBN 0-14303788-9, 2005.

[3] TC Group, Down on the Farm:The impact of nano-scale technologies on food and agriculture, pp. 1-8, 2004.

[4] Collingridge, The Social Control of Technology, New York: St. Martin's Press, pp.1-16, 1994.

[5] J. Lederberg, "Infectious History," Science, vol. 288, pp. 287-293, 14 April 2000.

[6] B. Hahn, Howard Hughes Medical Institute scientist, quoted in: Declan Butler, "Analysis of polio Vaccine could end dispute over how AIDS originated," Nature, vol. 404, pp. 9, 2 March 2000,.

[7] R. J. Bradbury, personal communication, 8May 2000, pp. 1-10. 